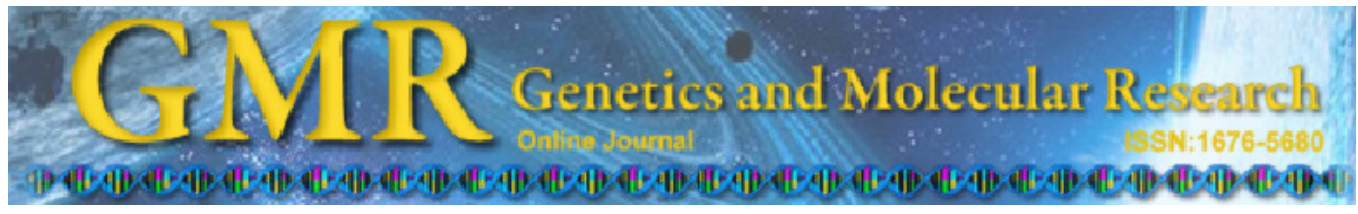

\title{
Production and identification of doubled haploids in tropical maize
}

\author{
G.M. Battistelli ${ }^{1}$, R.G. Von Pinho ${ }^{1}$, A. Justus ${ }^{1}$, E.G.O. Couto ${ }^{1}$ and \\ M. Balestre ${ }^{2}$ \\ ${ }^{1}$ Departamento de Agricultura, Universidade Federal de Lavras, Lavras, \\ MG, Brasil \\ ${ }^{2}$ Departamento de Ciências Exatas, Universidade Federal de Lavras, Lavras, \\ MG, Brasil
}

Corresponding author: M. Balestre

E-mail: marciobalestre@dex.ufla.br

Genet. Mol. Res. 12 (4): 4230-4242 (2013)

Received January 25, 2013

Accepted August 14, 2013

Published October 7, 2013

DOI http://dx.doi.org/10.4238/2013.October.7.9

\begin{abstract}
The production of maize doubled haploid (DH) lines is a technique commonly used by private companies, but not by Brazilian public institutions. Research on this technique is essential to develop and improve the production of $\mathrm{DH}$ lines grown under tropical conditions. We assessed the ability of a gynogenetic haploid inducer system to induce haploids in a tropical environment, assessed the induction rate of haploids identified using the R-navajo morphological marker, checked for interference from the generation of hybrid donors on haploid induction, measured the ability of flow cytometry, and simple sequence repeat marker techniques to identify doubled haploids. Seeds from the inducer Krasnodar Embryo Marker Synthetic (KEMS) line were sown in Ponta Grossa, PR, and Cravinhos, SP, and the plants were crossed to produce six hybrids and their $\mathrm{F}_{2}$ generations. The seeds were separated according to the R-navajo morphological marker indicator of haploidy (purple endosperm and white embryo) and germinated in a controlled environment. Chromosomal duplication was performed in seedlings selected as putative haploids. We performed subsequent confirmation of ploidy and the success of duplication using flow cytometry and SSR
\end{abstract}


marker techniques. We concluded that $\mathrm{DH}$ lines can be obtained from hybrids crossed with the inducer KEMS line. The generation of inbred hybrids did not affect the induction rate or chromosomal duplication in haploids. The use of flow cytometry and SSR markers was effective in verifying chromosomal duplication in haploids.

Key words: Haploidy inducer; Chromosome duplication; SSR; Flow cytometry; Doubled haploid lines; Hybrid maize

\section{INTRODUCTION}

Brazil is the third largest maize producer in the world, producing approximately 58 million tons of grain in the agricultural year 2010-2011 (Conab, 2011). The maize harvest area during this period was 13.84 million hectares, and over $90 \%$ of the seeds used for planting came from hybrid maize.

Multinational companies dominate the maize hybrid seed market, thereby withholding access to the latest technological innovations, such as transgenics and methods for obtaining doubled haploid (DH) lines. Therefore, information on the development of DH lines is restricted to private companies, which hinders access by national, public institutions.

Using haploid inducers to obtain DH lines enables the production of new hybrids in less time and at lower cost compared to traditional methods. The traditional method used to obtain lines requires at least six generations of self-pollination to reach homozygosity. This period can be shortened to 18 months using DH technology, which significantly increases both the competitiveness and dynamics of the genetic improvement program. This technique also enables the breeder to conduct the test cross with lines instead of inbred progeny. The implementation of this method requires the use of haploid-inducing lines that can produce paternal or maternal haploids, depending on the line used. In general, these haploid-inducing lines have a temperate origin, complicating their management and development under tropical conditions. The $\mathrm{F}_{1}$ generation genotypes are normally crossed with haploid-inducing lines, thereby accelerating the production of lines. However, Bernardo (2009) recommends the production of doubled haploid lines from the $\mathrm{F}_{2}$ generation to ensure an additional generation of recombination.

The identification of environments and sowing seasons favorable to the development of haploid-inducing lines is essential for a maize genetic improvement program aimed at producing hybrids from these lines, as well as the fast and inexpensive identification of putative haploids and the development of accurate methods for chromosomal duplication and methods for the production of lines following duplication. Flow cytometry is widely used because of the ease and speed of both sample preparation and result acquisition (Loureiro and Santos, 2004). Because it evaluates DNA content, flow cytometry is proving to be a great tool to help determine the efficiency of the haploid-inducing method and the success of chromosomal duplication. Other tools used in the identification of haploids include molecular markers, namely, microsatellites [simple sequence repeats (SSR)], because they are stable and co-dominant and allow for the separation of homozygotes from heterozygotes $\left(F_{1}\right)$ (Belicuas et al., 2007).

Thus, the aims of the current study were the following: i) to assess the haploid-inducing ability of the gynogenetic and androgenetic systems in tropical environments; ii) to evalu- 
ate the induction rate of haploids identified by the R-navajo (R1-nj) morphological marker; iii) to check for interference from the generation of hybrid donors in haploid induction; iv) to measure the ability of flow cytometry and SSR markers to confirm doubled haploids; and v) to obtain DH lines.

\section{MATERIAL AND METHODS}

\section{Experimental area}

The crossing fields were established in the municipalities of Cravinhos in the State of São Paulo (650 m altitude and $\left.21^{\circ} 20^{\prime} 25^{\prime \prime} \mathrm{S}, 47^{\circ} 43^{\prime} 46^{\prime \prime} \mathrm{W}\right)$ and Ponta Grossa in the State of Paraná ( $975 \mathrm{~m}$ altitude and $25^{\circ} 5^{\prime} 42^{\prime \prime} \mathrm{S}, 50^{\circ} 9^{\prime} 43^{\prime \prime} \mathrm{W}$ ). Laboratory procedures and seedling acclimatization were performed in the Department of Biology at UFLA located in the municipality of Lavras, which is situated in the State of Minas Gerais at $918 \mathrm{~m}$ altitude and $21^{\circ} 14^{\prime} 30^{\prime \prime} \mathrm{S}$, $45^{\circ} 00^{\prime} 10^{\prime \prime} \mathrm{W}$. Subsequently, the duplicated plants were grown in Ijaci, MG ( $830 \mathrm{~m}$ altitude and $\left.21^{\circ} 9^{\prime} 24^{\prime \prime} \mathrm{S}, 44^{\circ} 55^{\prime} 34^{\prime \prime} \mathrm{W}\right)$.

\section{Genotypes evaluated}

Six hybrids (30F53, DKB240, L3/DENT, 30/31, 43/48, and GNZ 2004) were used, and their $\mathrm{F}_{2}$ generations were crossed with two inducers. The haploid-inducing line, Wisconsin-23 (Kermicle, 1973) (androgenetic system), which carries the ig mutant allele and also alleles from the R-navajo system, was used as the female parent. The other inducer, the Krasnodar Embryo Marker Synthetic line (KEMS; Shatskaya et al., 1994), which also carries the dominant allele R1-nj (gynogenetic system), was used as the male parent. At each site, the hybrid seeds were sown 10 and 14 days before sowing the haploid-inducing lines to favor flowering synchrony, because the latter are of temperate origin and develop sooner. The crossing field in Ponta Grossa, PR, was established in the 2010-2011 crop, and in Cravinhos, SP, for the second crop of 2011. For each site, the inducers were sown in twenty 5-m rows to guarantee the minimal number of plants necessary for performing the crosses. The seeds from hybrids $\left(F_{1}\right)$ and their $F_{2}$ generations were sown in two 5-m rows. Two seeds per hole were distributed in rows spaced $80 \mathrm{~cm}$ apart, with $20 \mathrm{~cm}$ between plants. Thinning was performed approximately 15 days after plant emergence, leaving five plants per linear meter. The fields were fertilized at sowing with $500 \mathrm{~kg} / \mathrm{ha} 10-30-10$ formulation, and $500 \mathrm{~kg} / \mathrm{ha} 20-0-20$ were applied under coverage following thinning. The remaining harvesting practices were conducted as recommended for the maize crop.

\section{Production and identification of haploids}

The seeds obtained from the crosses listed above were dried to $13 \%$ moisture and visually separated on the basis of endosperm and embryo coloration. Grains with purple endosperm and white embryos were considered to be haploid and selected as described by Chase and Nanda (1965). The seeds selected based on the R1-nj morphological marker were incubated for $72 \mathrm{~h}$ in water-soaked germination paper in a Mangelsdorf-type germinator at a controlled temperature of $23^{\circ} \mathrm{C}$. Upon germination, the seedlings with low vigor and smaller 
radicles and coleoptiles were selected as putative haploids to eliminate false haploids prior to performing chromosomal duplication.

\section{Chromosomal duplication}

At the Cytogenetics Laboratory in the Department of Biology at UFLA, the low-vigor seedlings identified as putative haploids were subjected to chromosomal duplication treatment using a $0.06 \%$ colchicine and $0.5 \%$ dimethyl sulfoxide solution for $12 \mathrm{~h}$, according to the protocol proposed by Deimling et al. (1997). The only alteration to the protocol was not cutting the tips of coleoptiles.

Following the treatment with colchicine, the seedlings were washed for $20 \mathrm{~min}$ in running water and transferred to polystyrene trays with $1-\mathrm{cm}^{3}$ cells in plant substrate. The seedlings were acclimated in the greenhouse in the Department of Biology at UFLA, which is located in the municipality of Lavras in the State of Minas Gerais, situated at $918 \mathrm{~m}$ altitude and $21^{\circ} 14^{\prime} 30^{\prime \prime} \mathrm{S}, 45^{\circ} 00^{\prime} 10^{\prime \prime} \mathrm{W}$. The plants remained in a controlled environment for 20 days. During that period, foliar fertilization was conducted using $5 \%$ purified monoammonium phosphate.

\section{Chromosomal duplication assessment by flow cytometry}

The chromosomal duplication of haploid seedlings was confirmed at the Plant Tissue Culture Laboratory in the Department of Agriculture at UFLA using flow cytometry (Galbraith et al., 1983). Flow cytometry was performed 15 to 20 days after colchicine treatment. Young leaves $(20-30 \mathrm{mg}$ ) from the parents (the six hybrids and two inducers) and from the 918 progeny obtained from these crosses that survived chromosomal duplication were used for DNA content analysis by flow cytometry. An internal reference standard of 20-30 mg young leaves from Vicia faba (26.9 pg/2C) was used for each sample (Dolezel, 1997). To obtain a nuclear suspension, each maize seedling sample and $V$. faba sample were collected and fragmented using a scalpel on a Petri dish containing $1 \mathrm{~mL}$ ice-cold LB01 extraction buffer (Dolezel, 1997). The suspension was aspirated using a plastic pipette and gauze to prevent the passage of larger fragments of the plant tissue, and this mixture was then filtered through a nylon mesh $(50 \mu \mathrm{m})$ during transfer to a polyethylene tube. Extraction buffer $(25 \mu \mathrm{L})$ containing $1 \mathrm{mg} / \mathrm{mL}$ propidium iodide and $2.5 \mu \mathrm{L}$ RNase was added to the suspension at room temperature.

Each suspension was analyzed by flow cytometry (Becton Dickinson FACSCalibur). The histograms were analyzed using the Cell Quest and WinMDI 2.8 (2009) software programs. The estimated nuclear DNA content (pg) of each sample was performed by comparing the position of its G1 peak to the G1 peak of the internal reference standard whose DNA content was known.

The following equation was used for this comparison:

$$
\mathrm{Q}=(\mathrm{E} / \mathrm{S}) \times \mathrm{R}
$$

(Equation 1)

where $Q$ is the quantity of DNA in the sample (pg/2C); $E$ is the G1 peak position of the sample; $S$ is the G1 peak position of the reference standard; and $R$ is the DNA content of the standard (26.9 pg/2C).

To analyze the results, the mean amounts of DNA were calculated. Thus, the DNA amount enabled inference at the ploidy level of the material evaluated. 


\section{Chromosomal duplication assessment by tassel fertility}

After 20 days of the chromosomal duplication protocol, the plants were transplanted to an environment protected with a transparent plastic sheet cover on the HortiAgro Company premises located in the municipality of Ijaci, MG. All plants were identified to allow for tracking and comparing the cytometry results with the tassel fertility data. Seedling fertiliza-

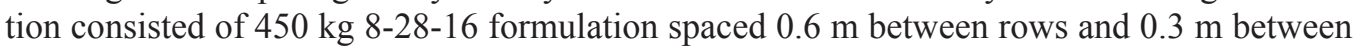
plants. Both the fertilization of the cover crop and the harvesting practices were conducted as recommended for harvesting in the region. The cobs were protected using plastic bags prior to the emergence of the style and stigma so that self-pollination could be performed later. Information on tassel fertility was collected for each plant after tassel emergence and classified as being either a fertile or sterile tassel. The pollen-producing plants were self-pollinated for seed maintenance and propagation.

\section{Chromosomal duplication assessment by microsatellites}

At the Molecular Genetics Laboratory in the Department of Biology, DNA from the inducer KEMS line was extracted from the six hybrids and the 65 plants from the cross between the inducer KEMS line and the hybrids. Sampling was conducted to collect DNA from plants that produced pollen and had green leaves and were classified as haploid, haploid/diploid, diploid, or diploid/tetraploid by flow cytometry. The extraction procedure was performed according to Pereira et al. (2007). Briefly, $3 \mathrm{~g}$ leaves was collected from each plant and ground using a mortar with liquid nitrogen, $10 \mathrm{~mL}$ extraction buffer, and $20 \mu \mathrm{L} \beta$-mercaptoethanol. The extraction buffer consisted of $2 \%$ CTAB, $100 \mathrm{mM}$ Tris, $\mathrm{pH} 8.0,1.4 \mathrm{M} \mathrm{NaCl}$, and $1 \%$ polyvinylpyrrolidone. The ground material was placed in centrifuge tubes and incubated in a $65^{\circ} \mathrm{C}$ water bath for $30 \mathrm{~min}$. The tubes were gently shaken during the incubation. After centrifugation, the supernatant containing the nucleic acids was collected. The nucleic acids were extracted using $10 \mathrm{~mL}$ chloroform:isoamyl alcohol (24:1) and precipitated by adding $30 \mathrm{~mL}$ $95 \%$ ethanol and $7.5 \mathrm{M}$ ammonium acetate $(6: 1)$. This mixture was placed in a $-20^{\circ} \mathrm{C}$ freezer for approximately $12 \mathrm{~h}$.

Following precipitation, the nucleic acids were transferred to microcentrifuge tubes, centrifuged, and dried. Subsequently, the nucleic acids were rehydrated in TE buffer $(1 \mathrm{mM}$ Tris and $0.1 \mathrm{mM}$ EDTA). Shortly after the second extraction with chloroform:isoamyl alcohol (24:1), the supernatant was precipitated by adding at least three volumes of $3 \mathrm{M}$ sodium acetate: $95 \%$ ethanol (1:20). The precipitated nucleic acids were rehydrated in TE buffer. A third extraction was performed with chloroform-isoamyl-alcohol using an equal volume of TE. The supernatant was collected and the DNA was precipitated (for approximately $12 \mathrm{~h}$ in the freezer) with sodium acetate alcohol until filling the tube $(1.5 \mu \mathrm{L})$. After centrifugation for $10 \mathrm{~min}$ at 10,000 rpm, the nucleic acids were rehydrated using TE buffer. Aliquots of DNA from each specimen were quantified on a $1 \%$ agarose gel alongside a standard DNA molecular weight marker from $\lambda$ phage DNA with the concentrations of 100,200 , and $300 \mathrm{ng} / \mu \mathrm{L}$. Upon visual comparison of the intensities of the DNA bands of the samples and standards, the DNA of each sample was quantified and the concentration subsequently adjusted to $10 \mathrm{ng} / \mu \mathrm{L}$ for use in the reactions.

Each PCR volume totaled $11.06 \mu \mathrm{L}$. This reaction was prepared by mixing the follow- 
ing reagents at the respective concentrations (Pereira et al., 2007): $2.25 \mu \mathrm{L}$ genomic DNA; 1 $\mu \mathrm{L}$ solution containing deoxyribonucleotide acids (dATP, dGTP, dCTP, and dTTP); $0.6 \mu \mathrm{L}$ Taq DNA polymerase; $0.8 \mu \mathrm{L}$ primer pair; $1.0 \mu \mathrm{L}$ reaction buffer $(50 \mathrm{mM}$ Tris, $\mathrm{pH} 8.3,2.0 \mathrm{mM}$ $\mathrm{MgCl}_{2}, 20 \mathrm{mM} \mathrm{KCl}, 10 \mu \mathrm{g} \mathrm{BSA}, 0.25 \%$ Ficoll 400 , and $10 \mathrm{mM}$ tartrazine); and $4.45 \mu \mathrm{L}$ bidistilled water to the final volume. Amplifications were performed in $0.2-\mathrm{mL}$ tubes on a Model Mastercycler Eppendorf thermocycler. The cycling program consisted of $5 \mathrm{~min}$ at $95^{\circ} \mathrm{C}$ for DNA denaturation, 8 cycles for $20 \mathrm{~s}$ at $94^{\circ} \mathrm{C}$ for denaturation, $20 \mathrm{~s}$ for primer annealing at $55^{\circ}$ or $60^{\circ} \mathrm{C}$ (depending on the primer tested), and $1 \mathrm{~min}$ at $72^{\circ} \mathrm{C}$ for DNA extension. We performed 24 cycles during which only the annealing temperature (from $52^{\circ}$ to $65^{\circ} \mathrm{C}$ ) differed from the initial cycles. In addition, there was a final extension step performed for 4 min at $72^{\circ} \mathrm{C}$.

The PCR products were subjected to vertical electrophoresis for $1 \mathrm{~h} 40 \mathrm{~min}$ at 130 $\mathrm{V}$ on a $6 \%$ polyacrylamide gel. After completion, the gel was stained using a silver nitrate solution for $10 \mathrm{~min}$, followed by rinsing in running water. The gel was then immersed in a developing solution until bands appeared, evaluated under fluorescent light, and photographed using a digital camera.

We used 25 primers indicated for the maize crop, according to Veiga et al. (2012) in a study of QTLs linked to resistance to cercospora disease and maize grain production. Of the 25 primers, 5 (BNLG 1175, BMC 1714, BNLG 1520, BNLG 1233, and BNLG 1258) were considered to be polymorphic between the parents, whose bands had good size and definition on the gel. These primers were used in the progeny to analyze and determine the paternity of haploids.

\section{Statistical analyses}

The analysis was performed using sites as replicates, and the observed ratios were evaluated using the generalized linear mixed model (GLMM) because overdispersion was detected. In this case, binomial GLMM with a logit link function was used, as described below:

$$
\begin{array}{cc}
\mathrm{R}_{i j k} / u_{i j k} \sim \frac{\operatorname{Binomial}\left(m_{i j k}, \pi_{i j k}\right)}{m_{i}} & \text { (Equation 2) } \\
\log \left(\frac{\pi_{i j k}}{1-\pi_{i j k}}\right)=\mu+\mathrm{l}_{\mathrm{i}}+\mathrm{h}_{\mathrm{j}}+\mathrm{g}_{\mathrm{k}}+\mathrm{hg}_{\mathrm{jk}}+\mathrm{P}_{i j k} & \text { (Equation 3) }
\end{array}
$$

where $R_{i j k} / u_{i j k}$ is the observed ratio in the plot that received the hybrid $\mathrm{j}$ in the generation $\mathrm{k}$ on site $\mathrm{i}$, presumed conditionally independent from the random effect plot; $\mu$ is the intercept; $l_{i}$ is the fixed effect of site $\mathrm{i} ; h_{j}$ is the fixed effect of hybrid $\mathrm{j} ; g_{k}$ is the fixed effect of generation $\mathrm{k}$; $h g_{j k}$ is the fixed effect of the interaction of hybrid $\mathrm{j}$ with the generation $\mathrm{k}$; and $P_{i j k}$ is the random effect of plot ijk, with $\mathrm{p}_{\mathrm{ijk}} \sim \mathrm{N}\left(0, \sigma_{\mathrm{p}}^{2}\right)$.

The GLMMs were adjusted by estimating the fixed and random effects, in addition to the variance components, through maximization of the restricted maximum likelihood function. The lme4 package of the R statistical software was used for this purpose. The significance of the effects from the model was verified by analysis of deviance by applying the $\chi^{2}$ (chi-square) statistical test at 5\% probability. Upon demonstrating the significance, especially 
for the hybrids and the interaction hybrids $\mathrm{x}$ generations, grouping was performed using the nearest neighbor method according to Mahalanobis distance, and the cutoff point was set using the bootstrap re-sampling procedure (Mourão Junior, 2001).

\section{RESULTS}

In this study, the W23 line had fewer seeds from putative haploids compared to the inducer KEMS line (Table 1). According to the likelihood ratio test at 5\% probability, there was a significant difference between the inducers in the haploid induction rate. The maternal haploid inducer KEMS line had a 7.1\% mean induction (Table 1), while the haploid induction rate of the W23 line characterized by the R-navajo ranged from 0 to $10 \%$ (Table 1).

\begin{tabular}{|c|c|c|c|c|c|c|c|c|}
\hline \multirow[t]{2}{*}{ Inducer } & \multirow[t]{2}{*}{ Hybrid } & \multirow[t]{2}{*}{ Generations } & \multicolumn{3}{|c|}{ Ponta Grossa, PR } & \multicolumn{3}{|c|}{ Cravinhos, SP } \\
\hline & & & Total & Haploids & Induction of haploids (\%) & Total & Haploids & Induction of haploids (\%) \\
\hline KEMS & $30 \mathrm{~F} 53$ & $\mathrm{~F}_{1}$ & 1781 & 118 & 6.6 & 1389 & 113 & 8.1 \\
\hline KEMS & $30 \mathrm{~F} 53$ & $\mathrm{~F}_{2}^{1}$ & 974 & 72 & 7.4 & 662 & 26 & 3.9 \\
\hline KEMS & DKB240 & $\mathrm{F}_{1}^{2}$ & 330 & 106 & 32.1 & 3745 & 106 & 2.8 \\
\hline KEMS & DKB240 & $\mathrm{F}_{2}$ & 1792 & 73 & 4.1 & 569 & 19 & 3.3 \\
\hline KEMS & L3/DENT & $\mathrm{F}_{1}^{2}$ & 1207 & 152 & 12.6 & 1100 & 107 & 9.7 \\
\hline KEMS & L3/DENT & $\mathrm{F}_{2}^{1}$ & 403 & 58 & 14.4 & 548 & 72 & 13.1 \\
\hline KEMS & $30 / 31$ & $\mathrm{~F}_{1}^{2}$ & 1574 & 207 & 13.2 & 1831 & 228 & 12.5 \\
\hline KEMS & $30 / 31$ & $\mathrm{~F}_{2}$ & 537 & 76 & 14.2 & 135 & 13 & 9.6 \\
\hline KEMS & $43 / 48$ & $\mathrm{~F}_{1}^{2}$ & 1668 & 113 & 6.8 & 2855 & 176 & 6.2 \\
\hline KEMS & $43 / 48$ & $\mathrm{~F}_{2}$ & 1306 & 110 & 8.4 & 1192 & 23 & 1.9 \\
\hline KEMS & GNZ 2004 & $\mathrm{~F}_{1}^{2}$ & 2067 & 383 & 18.5 & 2090 & 193 & 9.2 \\
\hline KEMS & GNZ 2004 & $\mathrm{~F}_{2}$ & 1191 & 378 & 31.7 & 2452 & 241 & 9.8 \\
\hline W23 & $30 \mathrm{~F} 53$ & $\mathrm{~F}_{1}^{2}$ & 532 & 23 & 4.3 & 1440 & 63 & 4.4 \\
\hline W23 & $30 \mathrm{~F} 53$ & $\mathrm{~F}_{2}$ & 404 & 11 & 2.7 & 821 & 7 & 0.9 \\
\hline W23 & DKB240 & $\mathrm{F}_{1}^{2}$ & 751 & 39 & 5.2 & 713 & 13 & 1.8 \\
\hline W23 & DKB240 & $\mathrm{F}_{2}$ & 409 & 36 & 8.8 & 587 & 2 & 0.3 \\
\hline W23 & L3/DENT & $\mathrm{F}_{1}^{2}$ & 438 & 44 & 10.0 & 407 & 3 & 0.7 \\
\hline W23 & L3/DENT & $\mathrm{F}_{2}$ & 139 & 13 & 9.4 & 255 & 0 & 0.0 \\
\hline
\end{tabular}

In the induction assessment of haploids identified by the R1-nj marker, significant differences were identified for the effects of sites and hybrids (Table 2). The non-significant effect of generations demonstrates that, even with one generation of inbreeding, there is no effect on the induction rate of haploids of hybrids, with no significant difference in the induction rate of haploids between one generation and the other. The percentage of induction assessed by the R1-nj marker varied significantly between hybrids. The GNZ 2004, L3/DENT, and 30/31 hybrids displayed the highest rates of haploid induction (Table 3).

Plants with various ploidy levels, including haploids, haploids/diploids, diploids, and diploids/tetraploids, were identified using cytometric analysis. Figure 1A displays the histogram of the parental donor, GNZ 2004, which was identified as being diploid, with a DNA concentration of $6.6 \mathrm{pg} / 2 \mathrm{C}$. Figure $1 \mathrm{~B}$ and $\mathrm{C}$ give examples of histograms from haploid and haploid/ diploid plants. Figure 1B illustrates the G1 peak of haploid cells from the sample having a DNA concentration of $2.8 \mathrm{pg} / 2 \mathrm{C}$, as estimated by comparison with the known DNA concentration of the fava bean ( $V . f a b a)$ control $(26.9 \mathrm{pg} / 2 \mathrm{C})$, provided by Dolezel (1997). By estimating the amount of DNA in the sample, it is evident that this amount was approximately half of the DNA 
concentration of the hybrid donor. In this example, the chromosomal duplication was found to be non-effective, considering the observation of the G1-phase peak only in haploid cells. The minor peak near the G1 peak of the sample is regarded as the G2 peak of the haploid cells.

Table 2. Summary of analysis of deviance of the induction rate of haploids identified by the R-navajo marker in six hybrids crossed with the inducer KEMS.

\begin{tabular}{lcc}
\hline Source & d.f. & Deviance \\
\hline Sites & 1 & $12.58^{*}$ \\
Hybrids & 5 & $15.56^{*}$ \\
Generations & 1 & 1.29 \\
Hybrids x Generations & 5 & 7.42 \\
\hline
\end{tabular}

*Significant differences are based on the $\chi^{2}$ test at 0.05 probability.

Table 3. Adjusted means of induction rates of haploids identified using the R-navajo morphological marker from the crosses of the six hybrids with the inducer KEMS.

\begin{tabular}{lc}
\hline Hybrids & Induction rate $(\%)$ \\
\hline 30F53 & $4.5^{\mathrm{b}}$ \\
DKB240 & $4.5^{\mathrm{b}}$ \\
L3/DENT & $9.0^{\mathrm{a}}$ \\
30/31 & $8.9^{\mathrm{a}}$ \\
43/48 & $3.7^{\mathrm{b}}$ \\
GNZ 2004 & $11.6^{\mathrm{a}}$ \\
\hline
\end{tabular}

Mean percentages followed by the same letter belong to the same cluster. Values are based on the Mahalanobis distance with a cutoff of $5 \%$ probability.

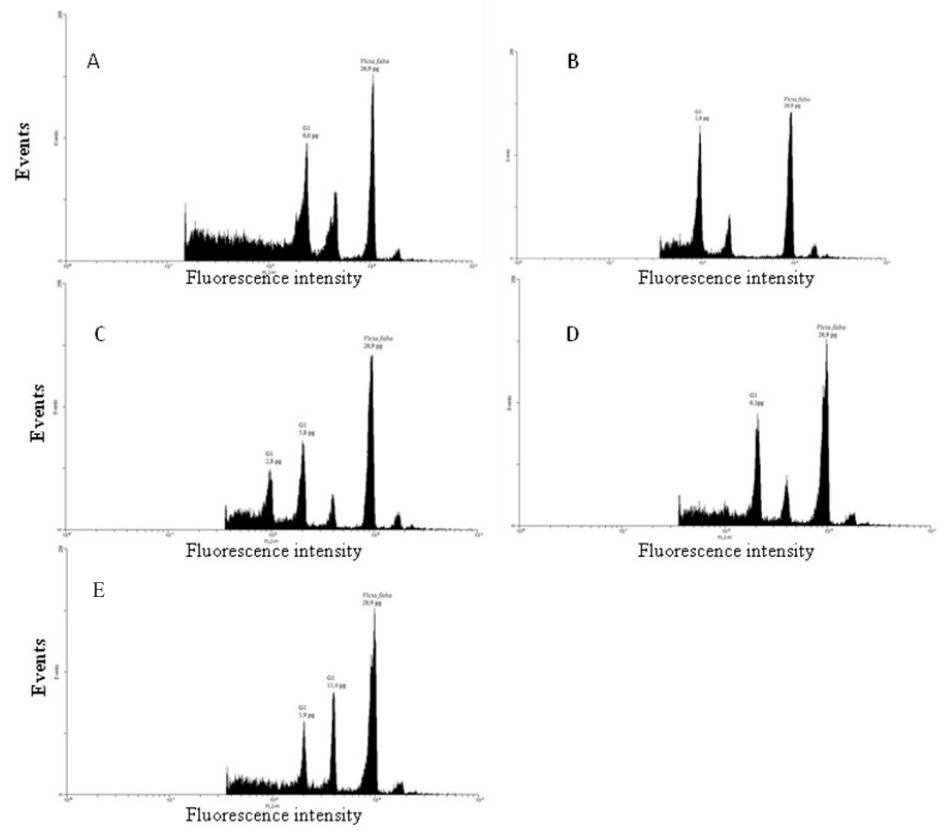

Figure 1. Flow cytometry histograms for the quantification of the DNA content of samples from maize leaves. A. Parental GNZ 2004 (diploid plant) and Vicia faba (standard sample) with a DNA concentration of $26.9 \mathrm{pg} / 2 \mathrm{C}$, B. Haploid plant. C. Haploid/diploid plant. D. Diploid plant. E. Diploid/tetraploid plant. 
Figure 1C histogram displays two high peaks considered to be the G1 peaks of the haploid and diploid cells. In this case, the plant has a variable number of chromosomes in the same tissue. Next to the G1 peak of cells classified as being diploid based on the amount of DNA, a small G2 peak in the same cells is visible. Therefore, the duplication was assumed to be successful in a portion of the cells of that plant. Other types of histograms displayed a G1 peak with an amount of DNA similar to that of the hybrid donors (Figure 1D), and these plants were considered to be diploid. Other plants had two G1 peaks, and these were considered to be diploid/ tetraploid (Figure 1E). These plants were not considered DH plants because it is believed that a completely diploid plant is difficult to obtain following induction of chromosomal duplication (Rotarenco V, personal communication). Thus, these plants were considered to be false haploids.

When evaluating the rate of haploid duplicates identified by flow cytometry, we observed a significant effect only for the hybrid $\mathrm{x}$ generation interaction. There was no significant difference for the remaining parameters (Table 4). The hybrids 30F53, L3/DENT, and GNZ 2004 demonstrated different behaviors between the generations (Table 5). The rate of duplication of hybrids 30F53 and GNZ 2004 was also higher in the $\mathrm{F}_{1}$ generation compared to the $\mathrm{F}_{2}$ generation. The opposite was shown by the L3/DENT hybrid, demonstrating that this situation varies between genotypes.

\begin{tabular}{lcc}
\multicolumn{2}{c}{ Table 4. Summary of analysis of deviance of the induction rate of doubled haploids identified by flow cytometry. } \\
\hline Source & d.f. & Deviance \\
\hline Sites & 1 & 0.99 \\
Hybrids & 5 & 4.92 \\
Generations & 1 & 0.61 \\
Hybrids x Generations & 5 & $13.64^{*}$ \\
\hline
\end{tabular}

*Significant differences based on the $\chi^{2}$ test at 0.05 probability.

\begin{tabular}{l}
$\begin{array}{l}\text { Table 5. Adjusted mean percentages of haploids with duplicated cells analyzed by flow cytometry of hybrids on } \\
\text { both generations and their overall mean. }\end{array}$ \\
\hline Hybrids \\
\hline F
\end{tabular}

Mean percentages followed by the same lower case letter on rows and upper case letter on columns belong to the same cluster. Calculations are based on the Mahalanobis distance at a cutoff of $5 \%$ probability.

Pollen production for self-pollination and seed production is a practical way of assessing the success of duplication in diploid plants. Summary of analysis of deviance (Table 6) displayed no significant difference for any of the effects evaluated. However, Table 7 presents the adjusted mean percentages of duplicated haploid plants that produced pollen.

\begin{tabular}{lcc} 
Table 6. Summary of analysis of deviance of the proportions of doubled haploids with fertile tassels. \\
\hline Source & d.f. & Deviance \\
\hline Sites & 1 & 0.19 \\
Hybrids & 5 & 5.83 \\
Generations & 1 & 0.88 \\
Hybrids x Generations & 5 & 10.69 \\
\hline
\end{tabular}

Significant differences based on the $\chi^{2}$ test at 0.05 probability. 
Table 7. Adjusted mean percentages of doubled haploids with fertile tassels.

\begin{tabular}{lc}
\hline Genotypes & Percentage \\
\hline 30F53 & $32.1^{\mathrm{a}}$ \\
DKB240 & $26.8^{\mathrm{a}}$ \\
L3/DENT & $18.3^{\mathrm{a}}$ \\
30/31 & $24.3^{\mathrm{a}}$ \\
43/48 & $19.6^{\mathrm{a}}$ \\
GNZ 2004 & $30.8^{\mathrm{a}}$ \\
\hline
\end{tabular}

Mean percentages followed by the same letter belong to the same cluster. Values are based on the Mahalanobis distance with a cutoff at $5 \%$ probability.

The SSR markers were used to confirm that duplicated plants, as confirmed by flow cytometry and pollen production, were actually haploid. The specimens with only bands from the hybrid donor were considered to be doubled haploids from haploid seeds, and plants with bands from the inducer and respective hybrid were diploids resulting from the cross. Examples of the band pattern of haploid duplicates from the hybrids 30/31 and 43/48, as confirmed by the markers, are displayed in Figures 2 and 3.

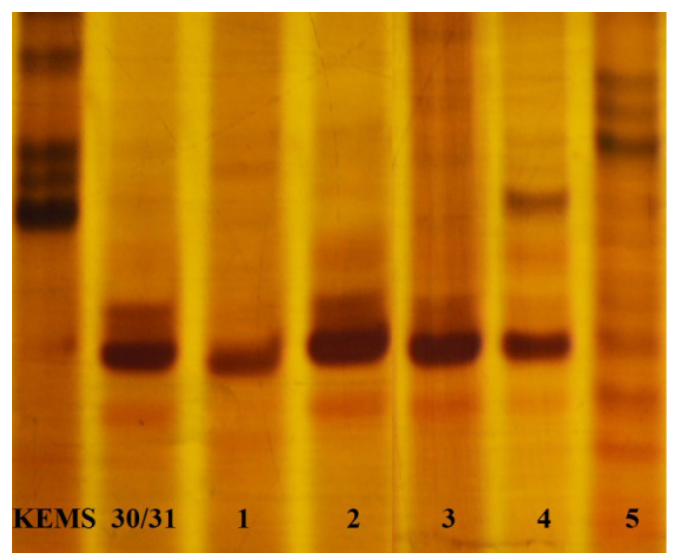

Figure 2. Amplification pattern with the SSR marker, bnlg 1233, analyzed on a $6 \%$ polyacrylamide gel. KEMS = haploid inducer; $30 / 31=$ hybrid; lanes 1,2 , and $3=$ doubled haploids; lanes 4 and $5=\mathrm{F}_{1}$ /heterozygotes.

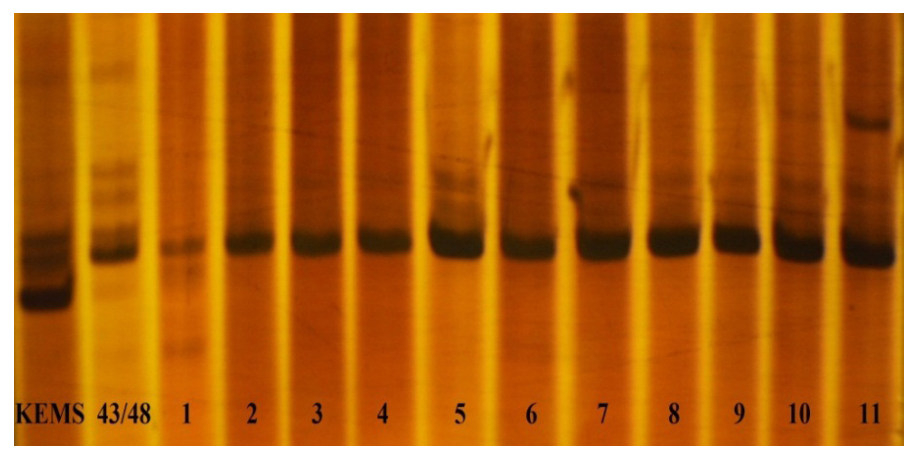

Figure 3. Amplification pattern with the SSR marker, bnlg 1175 , analyzed on a $6 \%$ polyacrylamide gel. KEMS $=$ haploid inducer; 43/48 = hybrid; lanes 1 to $11=$ doubled haploids. 


\section{DISCUSSION}

The adjusted means obtained by analysis of deviance of the induction rate in Ponta Grossa, PR, and Cravinhos, SP, were 16.9 and 9.2\%, respectively. The mean percentages of induction of the sites were higher than normally reported in crosses using this inducer (Shatskaya et al., 1994). Röber et al. (2005) used several inducers, including KEMS, and demonstrated significant differences between different environments. These authors stressed that the environment can influence the rate of induction in a variety of ways. However, Eder and Chalyk (2002) observed no significant difference in the induction rate between environments when they used the inducer MHI for the induction of haploids, either in a controlled environment or in the field.

Eder and Chalyk (2002), Röber et al. (2005), and Barbosa (2009) assessed several germplasms with different grain textures and determined differences in the induction rate of haplotypes between genotypes. Prigge et al. (2011) also reported significant differences between different germplasms. According to the authors, it is easier to identify haploids using the R1-nj morphological marker in hybrids compared to using the segregating populations. Thus, other methods for identifying haploids (e.g., seedling vigor, coleoptile coloration, the amount of oil in the embryo, and phenotypic characteristics of plants during their development) should be used to eliminate false-haploid specimens, as classified by the R1-nj marker.

Following chromosomal duplication, several seedlings did not survive until the sample collection period, most likely due to the toxic effect of colchicine. Therefore, cytometric analysis was performed on all plants that survived the colchicine treatment and remained alive until sample collection $(\mathrm{N}=918)$, which was approximately $62 \%$ of all treated plants. Dang et al. (2012) observed similar seedling survival results (65.7\%) in colchicine-treated waxy and opaque maize haploids. The authors noted that the surviving plants had twisted leaves with stunted growth during the first stage of development.

The rate of chromosomal duplication ranged from 59.1 to $80 \%$ (Table 5); however, the differences were not significant between hybrids. These results were higher than those obtained by Dang et al. (2012), who observed percentages from 28 to 54\%. These authors considered the duplication phase to be the most difficult time to obtain $\mathrm{DH}$ lines due to high mortality and low duplication rates. According to Dang et al. (2012), although colchicine is toxic to living organisms, its application in the production of DH continues to increase due to its efficiency in chromosomal duplication, and there is no other competitive chemical product for such purpose. However, Geiger and Schönleben (2011) assessed haploid plants from different sources of dentate elite germplasm and found several viable pollen-producing plants. Indeed, the authors performed flow cytometry on all plants analyzed and determined that some plants produced pollen. Thus, they concluded that in the long term, breeders could improve the ability of haploid plants to produce fertile tassels, thereby eliminating the artificial process of colchicine-induced chromosomal duplication.

Chalyk (2000) used maternal haploids and compared the efficiency of various methods of duplication to find the method with the greatest efficiency to produce a high percentage of DH lines with fertile tassels following duplication. Among the methods that the author studied, one had been previously proposed by Zabirova et al. (1996), and another had been proposed by Deimling et al. (1997). The percentages determined by Chalyk (2000) were 27.5 and $31.8 \%$. Eder and Chalyk (2002) obtained a mean percentage as high as $27.3 \%$ when compar- 
ing methods of duplication in different genotypes using the method proposed by Deimling et al. (1997). Although the percentage of plants with fertile tassels was within the values reported by several authors, this efficiency can be improved by perfecting some stages of the process.

We can infer from these results that it is possible to obtain DH lines from hybrids crossed with the inducer KEMS line; however, pre- and post-duplication management should be improved by seeking to increase efficiency in the production of $\mathrm{DH}$ lines. The production of DH lines using the inducer KEMS line (gynogenetic system) is favored under tropical cultivation conditions. The generation of inbred hybrids did not affect the rate of induction or chromosomal duplication. Finally, the use of flow cytometry and SSR markers is effective for the identification of doubled haploids.

\section{ACKNOWLEDGMENTS}

Research supported by Coordenação de Aperfeiçoamento de Pessoal de Nível Superior (CAPES), Conselho Nacional de Desenvolvimento Científico e Tecnológico (CNPq), and Fundação de Amparo à Pesquisa do Estado de Minas Gerais (FAPEMIG).

\section{REFERENCES}

Barbosa MPM (2009). Avaliação do Desequilíbrio de Ligação e da Origem Genética em Duplo-Haplóides de Milho. Dissertação. Universidade Estadual Paulista, Jaboticabal.

Belicuas PR, Guimarães CT, Paiva LV, Duarte JM, et al. (2007). Androgenetic haploids and SSR markers as tools for the development of tropical maize hybrids. Euphytica 156: 95-102.

Bernardo R (2009). Should maize doubled haploids be induced among F(1) or F(2) plants? Theor. Appl. Genet. 119: $255-262$.

Chalyk ST (2000). Obtaining fertile pollen in maize maternal haploids. Maize Genet. Cooperation Newslett. 74: 17-18.

Chase SS and Nanda DK (1965). Comparison of variability in inbred lines and monoploid-derived lines of maize (Zea mays L.). Crop Sci. 5: 275-276.

Compania Nacional de Abastecimento (Conab) (2011). Projeção Safra Brasileira 2010/2011. Available at [http://www. conab.gov.br/conabweb/download/sureg/RS11prevprodutiv.pdf]. Accessed May 29, 2011.

Dang NC, Munsch M, Aulinger I, Renlai W, et al. (2012). Inducer line generated double haploid seeds for combined waxy and opaque 2 grain quality in subtropical maize (Zea mays L.). Euphytica 183: 153-160.

Deimling S, Röber FK and Geiger HH (1997). Methodik und genetik der in-vivo-haploiden induktion bei mais. Vortr. Pflanzenzüchtung 38: 203-204.

Dolezel J (1997). Application of flow cytometry for the study of plant genomes. J. Appl. Genet. 38: 285-302.

Eder J and Chalyk S (2002). In vivo haploid induction in maize. Theor. Appl. Genet. 104: 703-708.

Galbraith DW, Harkins KR, Maddox JM, Ayres NM, et al. (1983). Rapid flow cytometric analysis of the cell cycle in intact plant tissues. Science 220: 1049-1051.

Geiger HH and Schönleben M (2011). Incidence of male fertility in haploid elite dent maize germplasm. Maize Genet. Cooperation Newslett. 85: 1-10.

Kermicle JL (1973). Androgenesis and the indeterminate gametophyte (ig) mutation: influence of pollen parent on androgenese frequency. Maize Genet. Cooperation Newslett. 47: 207-208.

Loureiro J and Santos C (2004). Aplicação da citometria de fluxo ao estudo do genoma vegetal. Boletim Biotecnol. 77 : 18-29.

Mourão Junior M (2001). Avaliação de um Critério Probabilístico em Análise Multivariada de Agrupamento (Cluster Analysis), por meio de Simulação Monte Carlo. Master’s thesis, Universidade Federal de Lavras, Lavras.

Pereira HS, Santos JB, Abreu AFB and Couto KR (2007). Informações fenotípicas e marcadores microssatélites de QTL na escolha de populações segregantes de feijoeiro. Pesq. Agropec. Bras. 42: 707-713.

Prigge V, Sanchez C, Dhillon BS, Schipprack W, et al. (2011). Doubled haploids in tropical maize: I. effects of inducers and source germplasm on in vivo haploid induction rates. Crop Sci. 51: 1498-1506.

Röber FK, Gordillo GA and Geiger HH (2005). In vivo haploid induction in maize - performance of new inducers and significance of doubled haploid lines in hybrid breeding. Maydica 50: 275-283. 
Shatskaya OA, Zabirova ER, Scherbak VS and Chumak MV (1994). Mass induction of maternal haploids in corn. Maize Genet. Cooperation Newslett. 68: 51-52.

Veiga AD, Von Pinho RG, Resende LV, Von Pinho EVR, et al. (2012). Quantitative trait loci associated with resistance to gray leaf spot and grain yield in corn. Ciênc. Agrotec. 36: 31-38.

Zabirova ER, Chumak MV, Shatskaya OA and Scherbak VS (1996). Technology of the mass accelerated production of homozygous lines (in Russian). Kukuruza Sorgo 4: 17-19. 